\title{
INNOVATIVE SYSTEM WITH SIMULTANEOUS ENERGY RECOVERY IN SHIPS FOR COMPLETE DESULPHURISATION OF EXHAUST GAS DERIVED BY HEAVY OIL
}

\author{
N. Pittas ${ }^{1}$, P. Koutsoukos ${ }^{2}$, Vasileios Moutsios ${ }^{3}$ and I. Muravieva ${ }^{4}$ \\ ${ }^{1}$ Mechanical Engineering and Aeronautics Deptartment, University of Patras 265 04, Pastra, Greece \\ ${ }^{2}$ Chemical Engineering Deptartment, University of Patras 265 04, Patras, Greece \\ ${ }^{3}$ Mechanical Engineering and Aeronautics Deptartment, University of Patras 265 04, Patras, Greece \\ ${ }^{4}$ School of Medicine, University of Patras 265 04, Patras, Greece
}

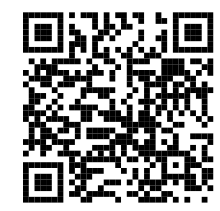

Received 24 June 2021

Accepted 9 July 2021

Published 20 July 2021

Corresponding Author

N. Pittas, P. Koutsoukos, npittas@u patras.gr

DOI $10.29121 /$

ijetmr.v8.i7.2021.989

Funding: This research received no specific grant from any funding agency in the public, commercial, or not-for-profit sectors.

Copyright: (C) 2021 The Author(s). This is an open access article distributed under the terms of the Creative Commons Attribution License, which permits unrestricted use, distribution, and reproduction in any medium, provided the original author and source are credited.

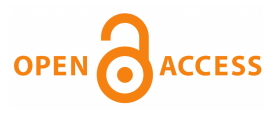

\section{ABSTRACT}

This paper presents an innovative worldwide method of total desulphurization of gas combustion-derived ships on heavy fuel diesel engines. For the treatment of waste aqueous solution derived from cationization with aqueous solution $\mathrm{NaOH}$ the exhaust gas and capture the $\mathrm{S}$ from $\mathrm{SO}_{x}$. For the treatment wastewater plant is necessary to have big surface and consumption biggest quantity of salt water. But unfortunately, the space free on the ships are very restricted and further consequently born stability problems for the ships. This proposal innovative methodology with new approx and new design overcame the limitations and the low performance of the actual scrubber systems and the negative provoked enormous environmental impact of these emissions and not complies the IMO international regulations. The method exposed in this paper overcame the requirement its international regulations of IMO

\section{N. Pittas Pittas (n.d).}

) (international maritime organization) and is Patent

Keywords: Sulfur, Exhaust Gases, Diesel Engines, Emission Dangerous, Environment, Ships

\section{INTRODUCTION}

In existing internationally installed scrubber systems, their efficiency for sulfur binding reaches up to $90 \%$ and there is no possibility to optimize them. Because seawater contains in 10 parts $8 / 10$ parts with calcium sulphate and $2 / 10$ of calcium carbonate. Therefore, huge quantities of seawater are required for cat ionisation, in order to absorb $\mathrm{S}$ released into the $\mathrm{SO}_{x}$ form from the diesel exhaust gases with heavy fuel content of S 3.5\%. Consequently, the amount of seawater required for cationization of the exhaust gases of about $68,000 \mathrm{Nm}^{3} / \mathrm{h}$ by a vessel of 60,000 tones is 500 tones per 
hour with a maximum desulphurization of $90 \%$, whereas with the proposed method only 20 tones per hour and in total desulphurization 99.7\%. In that it involves energy, ergonomics, construction and cost for a ship.

Exhaust gas from the ship's chimneys contains SOx, NOx and other volatile hydrocarbons because of combustion. The concentration of SOx in the gases is high because the $\mathrm{S}$ content in heavy fuel oil reaches up to $4 \%$. In order to achieve a high cleaning performance, the temperature of the exhaust gases containing SOx must be low because otherwise the degree of saturation of the droplets will be low and therefore the efficiency of precipitation of SOx will be low.

Their velocity must exceed $3 \mathrm{~m} / \mathrm{s}$ to achieve complete mixing of the gases with the droplets of the $\mathrm{NaOH}$ alkaline solution and to precipitate the SOx in the form of sodium sulfate and sulphite. This is because the size of the gas molecules is orders of magnitude smaller than the size of the solution molecules. And according to statistical thermodynamics, the impingement-mixing potential of these two fluids becomes more likely if their particle size fluctuates at about the same level. And in order to reduce the droplet size order of the alkaline solution, so that the difference does not exceed two orders of magnitude, we inject at high pressure which means high droplet velocity, so as to minimize droplet size and the contact surface will increase. And so this contact will be achieved which will result in the precipitation of the sulfur contained in $\mathrm{SO}_{3}$ and first converted to $\mathrm{H}_{2} \mathrm{SO}_{4}$ and then converted to $\mathrm{Na}_{2} \mathrm{SO}_{4}$ according to the following chemical reactions:$$
\mathrm{SO}_{3}+\mathrm{H}_{2} \mathrm{O} \rightarrow \mathrm{H}_{2} \mathrm{SO}_{4}
$$$$
\mathrm{H}_{2} \mathrm{SO}_{4}+\mathrm{NaOH} \rightarrow \mathrm{Na}_{2} \mathrm{SO}_{4}
$$

In addition, it should be noted that the temperature of the exhaust gas varies between $450{ }^{\circ} \mathrm{C}$ and $430{ }^{\circ} \mathrm{C}$ and to reduce this temperature as much as possible to $160^{\circ} \mathrm{C}$, in order to increase the degree of saturation, that is to say, why the capture of $\mathrm{S}$ from $\mathrm{SO}_{x}$ in the form of $\mathrm{Na}_{2} \mathrm{SO}_{4}$ or $\mathrm{Na}_{2} \mathrm{SO}_{3}$ a cationization scrubber process that will requires a low amount of water and not requirement large amount of water to be evaporated to further reduce the gas temperature.

And if used

1. Desalinated water in order to avoid operating complications and to avoid large amounts of salt resulting from evaporation, due to the need to use many cubic meters of water will increase operating costs, such as electricity for the reverse osmosis process.

2. Sea water will cause complications in the operation of the unit due to the deposition of $\mathrm{Ca}_{2} \mathrm{SO}_{4}, \mathrm{Ca}\left(\mathrm{CO}_{3}\right)_{2}$ salts on the scrubber as well as the upstream venturi tube. 
The heat produced to be abducted by a diesel engine e.g. $10 \mathrm{MW}$ equals $\mathrm{Q}=\mathrm{m} \mathrm{cp} \Delta \mathrm{T}$ $=75,000 \mathrm{~kg} \times 0.24 \mathrm{kcal} / \mathrm{kg} \cdot{ }^{0} \mathrm{C}\left(430{ }^{0} \mathrm{C}-250{ }^{0} \mathrm{C}\right)=3,240,000 \mathrm{kcal} / \mathrm{h}$.

We can, with an energy recuperator, and in particular a water / exhaust heat exchanger, reduce - freeze - recover part of the huge energy lost by saving fuel for the propulsion of the ship and at the same time reducing the temperature of the gases which is our primary goal. This is achieved as follows:

At the ship's chimney, and in particular at the appropriate level of the ship, we carry out a bypass, in order to divert and force the flow of exhaust gas to pass through a flow-through heat exchanger through the tubes, and the water outside them, as illustrated in Figure 1 and the cross section thereof.

We cannot reduce further the temperature of the exhaust gas from the funnel, because there is a risk of liquefaction of the catramic substances contained in the exhaust gas and their deposition on the tubes of the heat exchanger Figures 1 and ?? , which will then pass drastically reduce the heat transfer coefficient to water. This is why we limit ourselves to eg $250{ }^{\circ} \mathrm{C}$, to ensure timeless operation of the unit while avoiding any problematic maintenance and at the same time save energy equal to $\mathrm{Q}=$ $\mathrm{m} \mathrm{cp} \Delta \mathrm{T}=75,000 \mathrm{~kg} \times 0.24 \mathrm{kcal} / \mathrm{kg} \cdot{ }^{0} \mathrm{C} \times\left(430{ }^{0} \mathrm{C}-250{ }^{0} \mathrm{C}\right)=3,240,000 \mathrm{kcal} / \mathrm{h}$ with $\mathrm{Q}=3,240,000 \mathrm{kcal} / \mathrm{h}$, which given that the lowest calorific value of fuel oil equals $8,000 \mathrm{kcal} / \mathrm{h}$, corresponds to a saving of $405 \mathrm{~kg} / \mathrm{h}$ fuel oil. The steam produced by the heat exchanger is $5,800 \mathrm{~kg} / \mathrm{h}$, of which $1000 \mathrm{~kg} / \mathrm{h}$ will supply the heating system for liquefaction of the fuel oil and remain $2,240,000 \mathrm{kcal} / \mathrm{h}$ to be fed into the steam turbine for power generation.

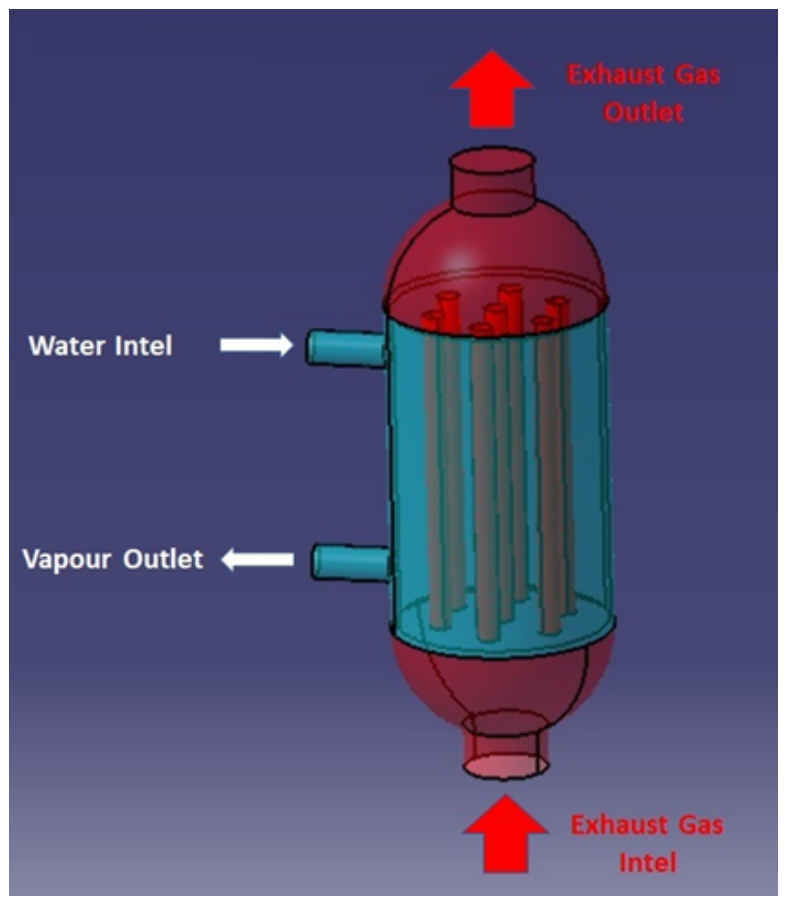

Figure 1 
This means first that the steam generated by recovery will eliminate the use of the fuel oil-consuming steam generator to preheat and liquefy the fuel required to enter the diesel engines and secondly by introducing the excess steam energy into that steam engine for the propulsion of the ship or completely for the operation of the power generators of the high-power ship. Due to the high speed of the steam turbine shaft at 5,200 rpm it will mate with a gear unit $\frac{1}{2}$ to mate with the generator whose speed is 2,400 rpm. The power of the steam turbine with the above assumptions for both this case and the given propulsion power will be $0.5 \mathrm{MW}$. The circuit is closed, and the water is deionized.

It should also be noted that using a 0.5-liter diesel fuel with a much lower S concentration that relieves us of the risk of catastrophic deposition, we can reduce the exhaust temperature of the gases e.g. from $250{ }^{\circ} \mathrm{C}$ to $130{ }^{\circ} \mathrm{C}$ and thus result in $\Delta \mathrm{T}$. $=430{ }^{0} \mathrm{C}-130{ }^{0} \mathrm{C}=300{ }^{0} \mathrm{C}$ and which translates into energy savings $\mathrm{Q}=\mathrm{m} \mathrm{cp} \Delta \mathrm{T}=$ $75,000 \mathrm{~kg} \times 0.24 \mathrm{kcal} / \mathrm{kg} .{ }^{0} \mathrm{C}\left(430{ }^{0} \mathrm{C}-130{ }^{0} \mathrm{C}\right)=5,400,000 \mathrm{kcal} / \mathrm{h}$. And because the resulting vapor is $10,000 \mathrm{~kg} / \mathrm{h}$ and the power $\mathrm{P}=\mathrm{M} \times \Delta H \times \eta_{\tau} / 860=M \times \Delta H / 1000$ with $\eta_{\tau}=0.86$ results in $0.8 \mathrm{MW}$.

The energy saved by the operation of ships increases with the power of propulsion diesel engines. This means that the ship's energy-saving and power system can function independently, if there is no need to eliminate SOx.

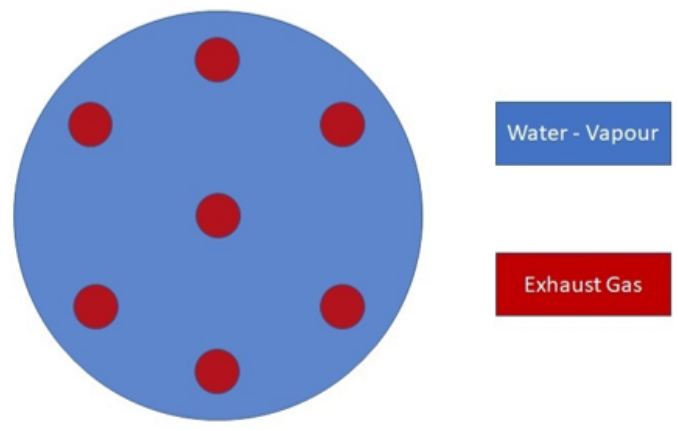

Figure 2

\section{METHODOLOGY}

The function of the device is as follows: We place on the deck or in an appropriately sized water / exhaust heat exchanger. From where the inlet water enters at $15^{\circ} \mathrm{C}$ and vaporizes at $250{ }^{0} \mathrm{C}$, the exhaust gas enters at $430{ }^{\circ} \mathrm{C}$ and exits at $250{ }^{\circ} \mathrm{C}$ and enters the upper end of the venturi tube and is then driven to the lower end of the scrubber. This cationization in the scrubber will be carried out in two steps, so that any amount of gases has escaped from the first stage of treatment to undergo the second stage and thus achieves complete SOx precipitation. Upon the passage of the exhaust gases from the first stage, a VENTURI tube will be installed upstream of the 
exhaust gases and there will be a cationization system with the same alkaline solution in order to reduce the temperature of the gases from $430{ }^{\circ} \mathrm{C}$ to $(180-170){ }^{0} \mathrm{C}$.

The cationization water will come from seawater supplied with submersible pumps and after passing through a reverse osmosis desalination system, an appropriate amount of $\mathrm{NaOH}$ will be added so that the resulting solution is alkaline at the appropriate $\mathrm{pH}$. This alkaline solution will be poured under appropriate pressure perpendicular to the turbulent flow of the exhaust gas, to prevent the passage of untreated exhaust gas to the atmosphere.

The particles as well as the oily and catramics precipitates together with the aqueous solution now containing sodium sulfites are taken to a collection tank in which the oily and catramics substances float and through a separator we drive them through substances in an appropriately sized tank that will be disposed of in a port for further processing. The treated water because it is at a higher temperature through a seawater heat exchanger (14), in reverse flow will reduce its temperature. After they enter the venturi tube and undergo a pretreatment, that is, a first cationization with an alkaline $\mathrm{NaOH}$ solution. Then through the duct coupling the outlet exhaust will enter the first stage of cationization with the same alkaline solution and after complete mixing of the exhaust gas molecules with the droplet cloud of the alkaline solution, leaving the first stage lateral of the first with the same alkaline solution. Then $99.7 \%$ free of $S$ are released into the atmosphere.

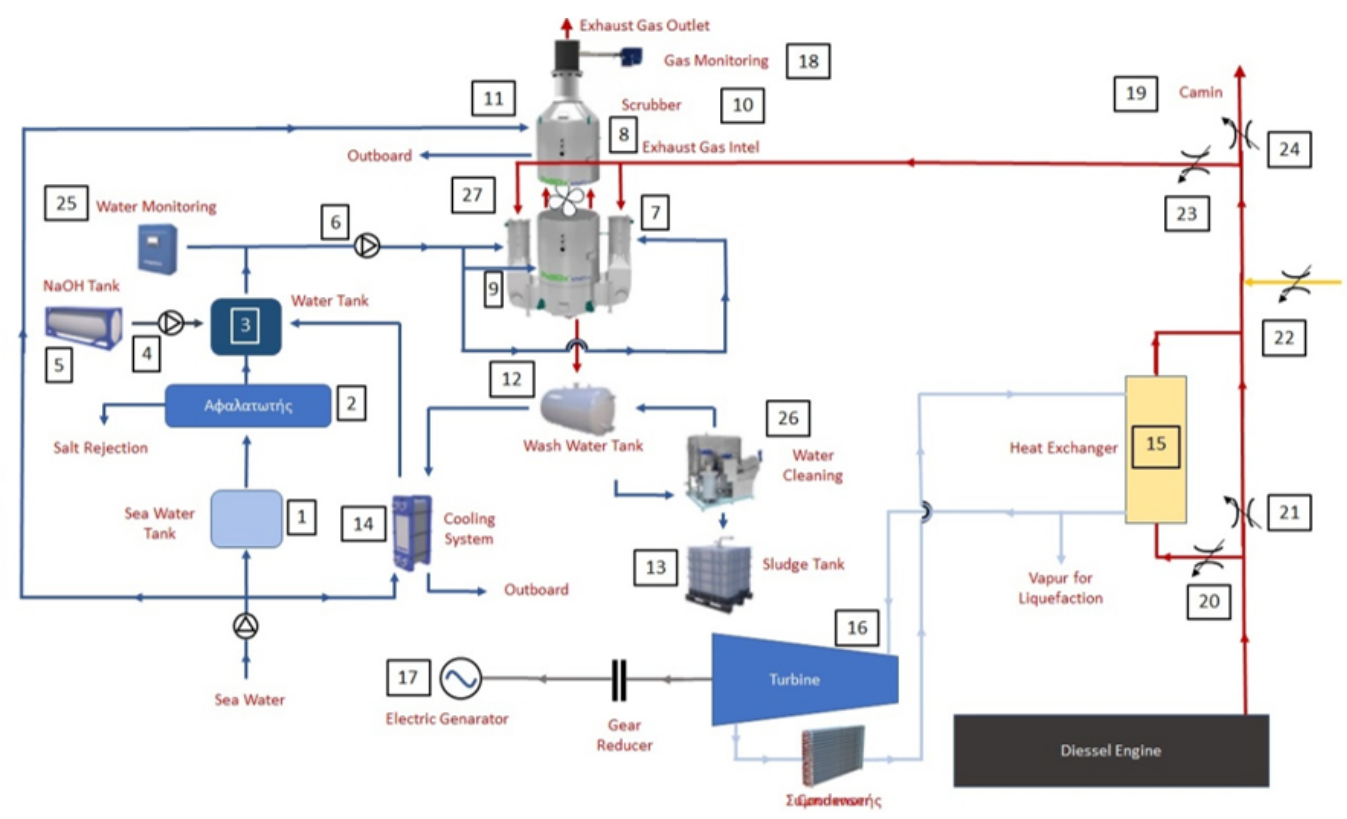

Figure 3

It should be noted that the above calculations for a specific ship power of $10 \mathrm{MW}$ were made to make the method and idea clear and understandable. But the SOx methodology and process of simultaneous energy recovery are still unchanged for 
any ship propulsion force. Exhaust gas passage cleaning is achieved by removing the heat exchangers lids and using a brush.

The operation description of the unit is as shown in Figure 3.

\section{APPLICATION}

The unit is operated, and the submersible pumps are fitted to each ship and transport sea water from sea level to the tank (1) on deck. From this tank, water is pumped to pass through the desalination system (2) with double stages membranes and the bulk is discharged into the sea, and desalinated water is placed in a tank (3) where a dosing pump (4) is poured into $\mathrm{NaOH}$, so that the $\mathrm{pH}$ of the resulting aqueous solution is of the desired degree of alkalinity using the alkalinity control system (25). The metering pump feeds the caustic soda from the special tank (5) containing $\mathrm{NaOH}$. From the reservoir (3) through a pump (6) at a suitable pressure are fed three positions for cationization of the exhaust gases and which are the first downstream (7) of the exhaust gas inlet into the venturi tube (8) in the pretreatment phase. The second is the first stage (9) of the scrubber treatment-cationization (10). And in the third position (11) which is the second cationization stage of the scrubber.

It should also be noted that the alkaline solution ejectors will be properly designed and operated so that the ejection is perpendicular to the exhaust gas flow and a turbulent flow is created to increase turbulence with the ultimate goal of maximizing surface area. mixing of molecular droplets and molecular gas aggregates, for the effective precipitation of $S$. The exhaust gases after passing through the venturi tube and then passing through the first and second cationization stages will exit the atmosphere at about $(70-80){ }^{0} \mathrm{C}$, free of $\mathrm{S}$.

The wash water residues along with the particles and the oily and catramics substances will be collected in a tank (12), from which the floating oily and catramics substances will be immediately separated and stored in another tank (13) for delivery to the selected tank. and the washing waters having a temperature ranging between (80-90) ${ }^{0} \mathrm{C}$ are directed to a heat exchanger (water / water) (14) to which the heat of the wash water is extracted, through seawater at a temperature of about $15^{0} \mathrm{C}$, enter the tank (3) recycled water at the same temperature.

In this way the demand for desalinated water and consequently energy consumption becomes minimal as well as that of caustic soda, because the $\mathrm{pH}$ of the recycled water is alkaline. Every hour the total water used is completely renewed. The amount of water used is minimal compared to what exists and this results in the cost of operating the device.

Keeping the efficiency of neutralization unchanged over time.

At the same time, the exhaust gases from the diesel engine entering the heat exchanger (15) (air / water) transfer their thermal load to the water which is vaporized and whose vapor is sufficiently supplied first to the fuel oil system, with which it is equipped with all ships using heavy fuel. 
The rest of the steam mass is fed by a steam turbine (16) with a suitable reducer coupled to it by the generator (17). Exiting the by-pass gases and entering the starting chimney, we create a misleading outlet to the chimney (22) on the chimney, to prevent a back pressure on the diesel engine. The exhaust due to the vacuum created by the venturi tube will be absorbed to the exit of the scrubber by bringing with them an amount of ambient air which will act beneficial by reducing the exhaust temperature and making it suitable for cationization treatment. Upstream of the misleading exit there will be another bypass from the chimney (by pass), equipped with pneumatic valves (23), (24) through which the exhaust gases lead to the venturi-scrubber cat ionization system (10) and exit the venturi-scrubber (10). S exhaust gas. There will be two on-off pneumatic valves (23), (24) which will allow automatic return to the previous operating state.

\section{THEORETICAL ANALYSIS}

For a ship SUEMAX class 70.000 tons we have. The quantity of $S$ in the exhaust gases is $59.5 \mathrm{~kg} / \mathrm{h}$. Acceptable quantity of $S$ after the treatment must be max $0.1 \%$, in agreement with rules IMO. The quantity of $S$ content inside the combustible heavy fuel is $3.5 \%$. Hence the relation of cationization is 35 . The quantity of S exit after the treatment become $1.7 \mathrm{~kg} / \mathrm{h}$.

Volume exhaust gases at $80^{\circ} \mathrm{C} 68,000 \mathrm{~m}^{3} / \mathrm{h}$. The calculus based in $1 \mathrm{~h}$

We suppose all the quantity of S (in sulphate) bonded into $25 \mathrm{~m}^{3}$ (2380 ppm). This is the max flow rate treatment in the unit RO (Reverse Osmosis) (Advance Technical). Initial concentration after the absorption from cationization with alkaline solution ( $\mathrm{pH} 10$ ) originating from the unit in RO (reverse osmosis) from sea water with the composition shown in Table 1.

\begin{tabular}{ccc}
\hline Table 1 Composition of sea water. & & \\
\hline species & ppm & mol/L \\
$\mathrm{B}$ & 69 & $6.4 \times 10^{-3}$ \\
$\mathrm{Ba}$ & 0 & 0 \\
$\mathrm{C}$ (carbonates, $\mathrm{HCO}_{3}{ }^{-}, \mathrm{CO}_{3}{ }^{2-}$, & 5.8 & $9.69 \times 10^{-5}$ \\
$\left.\mathrm{CO}_{2}\right)^{-}$ & & \\
$\mathrm{Ca}^{2+}$ & 0.56 & $2.553 \times 10^{-3}$ \\
$\mathrm{Cl}^{-}$ & 90.27 & $5.13 \times 10^{-5}$ \\
$\mathrm{~F}^{+}$ & 0 & 0 \\
$\mathrm{~K}^{+}$ & 2 & $5.3 \times 10^{-5}$ \\
$\mathrm{Mg}^{2+}$ & 1.51 & $6.23 \times 10^{-5}$ \\
$\mathrm{NO}_{3}{ }^{-}$ & 0.09 & $6.44 \times 10^{-6}$ \\
$\mathrm{Na}^{+}$ & 54.68 & $2.385 \times 10^{-3}$ \\
$\mathrm{SO}_{4}{ }^{2-}$ & 2,380 & $2.484 \times 10^{-2}$ \\
$\mathrm{Si}$ & 0.02 & $3.337 \times 10^{-7}$ \\
$\mathrm{Sr}^{-5}$ & 0.01 & $1.144 \times 10^{-7}$ \\
\hline
\end{tabular}


Thermodynamic calculus based on the equilibrium software MINEQL+ (Environmental Research Software Inc)

From the above calculus and supposing all the sulphate salts solution from metals included in aqueous phase, become the residual $\mathrm{S}$ into solution is $14 \mathrm{ppm}$, that is $0.5 \%$ or in other words removed $99.5 \%$ from the initial quantity of $\mathrm{S}$. If we take account the water loosing from the absorption -evaporation $\left(25-4.6=20.4 \mathrm{~m}^{3}\right)$, the corrected residual concentration become $17 \mathrm{ppm}$. In other words, removing $\mathrm{S}$ at 99.3\%. Repeated the calculus with flow rate $20 \mathrm{~m}^{3} / \mathrm{h}$ from RO and the same composition gave after correction $0.30 \mathrm{ppm}$ final concentration, become $99.7 \%$.

Running the program with assumption flow rate water exit from $\mathrm{RO} 25 \mathrm{~m}^{3} / \mathrm{h}$, the residual concentration of S (sulphate) become $55.55 \mathrm{ppm}$, removing $97.7 \%$.

\section{CONCLUSIONS}

This system independently achieves the elimination of S completely $99.7 \%$ from exhaust gas with simultaneous energy recovery. This result is very important why complies completely the requirement of IMO guidelines. IMO guidelines stipulate that the retention rate of $S$ from exhaust gases from funnel must not be less than $90 \%$.

With this innovation system overcame the limit superior requirement of IMO.

Further the requirement of water by the proposal system for the cat ionization is the $5 \%$ in volume of the respective systems which used today. This have as consequence the minimization of consumed energy to function the pumps.

\section{REFERENCES}

IMO (international maritime organization rules). (n.d.).

Pittas, P. N. (n.d.). OBI 20190100160. 